\title{
Philosophical Meaning of Modern Transformations of Education
}

\author{
Tatiana Leshkevich \\ Southern Federal University \\ Rostov-on-Don, Russia \\ E-mail: Leshkevicht@mail.ru
}

\begin{abstract}
The article is devoted to a critical examination of modern transformations in the educational process. The author seeks to substantiate the philosophical meaning of modern transformations. The article draws attention to four main aspects. First, the article reveals the shortcomings of the modern educational model based on competencies, which, having a formal character, control the free manifestation of personality. Secondly, the advantages of "paideia", which unites education, training and culture, are shown. Attention is drawn to the meaning and potential of the model of personal knowledge. Thirdly, the article describes a wide range of basic methodological approaches. The focus of attention is shifted to heuristic methods and cognitive practices that are related to motivation and a value-oriented approach. Fourth, the negative effects of the info-centric world are critically analyzed. The author shows the deformations of the cognitive structure of thinking, which arise in the conditions of the infocentric world. The conclusion in the article is that the philosophical meaning of the transformations of the educational process is based on philosophical wisdom and the ideals of genuine humanity. In this connection, the article highlights the significance and role of the socio-humanitarian examination.
\end{abstract}

Keywords-competences; personal knowledge; methodology; negatives of the info-centric world

\section{INTRODUCTION}

The modern paradigm of education relies on the intellectual capital. Despite the huge flow of information, it requires the highly intellectual development from the younger generation. The declared level of the modern educational paradigm is raised considerably. It is not satisfied with the alphabetical set of disciplinary knowledge, but involves the awareness of all existing issues, the orientation to novelty, the heuristics and originality of thinking. However, the meaning of all educational transformations, new techniques and techniques is pushed aside in the background.

Although the reflection on the educational process is one of the characteristic features of the social development. A number of modern researches emphasize the role of the philosophy of education, which provides critical reflection on the problems of the educational process, puts forward new guidelines for the reorganization of the education system and articulates the new value ideals[1]. The focus is on the analysis of creative techniques and methods of education. The focus is on creative [2]. The theory of developmental learning continues to arouse interest also.[3]

The conclusion that the human culture endures internal degradation can be disproved only on the basis of formation of worthy younger generation as carriers of new morality. The system of true humanistic values has to penetrate the strategy of education. The world models of the future should be based on genuinely humanistic man-oriented programmes [4. PP.14-22]. At the same time, as the researchers note, the ethnocultural, linguistic, economic and social disunity is growing within the Russian educational system. The disagreement between the universal and national attitudes, the inconsistency of the various pedagogical norms, manifests itself [5. P.4]

Thuch, in our opinion, the main goal is to substantiate the meaning of the transformations of the educational process on the basis of philosophical wisdom and the ideals of genuine humanity.

\section{THE EDUCATIONAL PARADIGM: TURN TO COMPETENCES}

At the present time, the focus of the modern educational process is shifted to the competences, which form three abilities: to know, to be able, to own. The concept of "competence" was not immediately accepted by the university community of teachers. In general, it means the capability to solve a number of certain professional tasks and to conform to official requirements.

Under the pressure of competitiveness, the knowledge transfer system has been fundamentally changed. It should be oriented on the formal standards. The standards have appropriated to themselves a dominant role in all spheres of the educational space. At the same time the students as subjects of educational process were reduced to a role of a peculiar construction material.

The drawbacks of competencies are that they essentially restrict the scope of individual achievements to formal instructions. They determine the direction of development and control the free manifestation of personality. The conceptual scheme assigned to the competences has a significant influence on the cognitive process itself. 
As a result, it turns out that the formal standards overcame the idea of harmonious development of the personality. While all progressive humanity considers the idea of the all-round development of the personality as the main reference point and an ideal. This is the main goal of the world-historical process. This idea embodies the main goal of the world-historical process. A person, who aspires to self-realization and self-improvement, is necessary for the development of the society.

The education is a way of purposeful social inheritance. Let us emphasize that Hegel assessed education as the sphere of organic merger between what is real and what is due. Like Aristotle, he believed that ethics had a directing social dimension.Summing up what has been said, it should be noted that the competences adopted for the governing schemes of modern are the products of the existing educational system. They have the status of concrete historical idealizations and can be estimated as a peculiar type of an "eksperimentalizm" [6].

\section{III. "PAIDEIA" AS A PHILOSOPHICAL MODEL OF EdUCATION AND MODEL OF PERSONAL KNOWLEDGE}

In contrast to the negatives of modern transformations in the education system, attention should be paid to the 'Paideia' model, which has a historical authority. The ancient model of Paideia unites three components: education, training and culture. As the commentators note, the concept of "Paideia" arose among the Sophists in the 5th century. BC, and was developed y Plato. The ideas of "Paideia", which combines education, training and culture, fixes the process of forming of human virtues.

This model comprised norms, regulations and cultural installations that contribute to the formation of a set of positive human qualities. Paideia was not limited to intellectual exercises and the process of accumulating knowledge. Such abilities as ability of judgment, aesthetic sense, ethical virtues, the study of grammar was supplemented by studying music and practicing gymnastics. In antiquity, Paideia was valued so highly that Plato came to a conclusion in the "Phaedrus" dialogue. The soul takes away only Paideia to the next world. The Paideia model was aimed at the reproduction, if not the ideal, then a worthy sample. It reproduced and transcended the sociocultural code.

It is important to note that the Paideia model included a clearly expressed function of care. Now this feature is absent in many educational models. The system of competences does not even mention this function. However, we emphasize that this function manifests itself more concentrated in small spatial and organizational forms than in large-scale ones [7. PP. 775-777].

Moreover, in the conditions of antagonistic societies the idea of a harmonious development of the individual is completely dissipated. According to our opinion, the function of care should be directed to the study of the spiritual sphere, it is not limited only to material support.
Unfortunately the ancient model of Paydaia was lost. However, modern philosophers, psychologists, scientists and teachers are working to create such models of the educational process, in which its humanitarian potential would be particularly significant.

The positive shifts in the education process are associated with the goal of enriching each individual with the personal knowledge. Undoubtedly, the personal knowledge is a special kind of value, connected with the skills and abilities. The phenomenon of personal knowledge was considered by M. Polani[8]. However, even Plato was interested in such fundamental questions as: what knowledge is, whether virtue can be taught, what virtue is, what the relation between knowledge of virtue and being virtuous is? [9. P.584].

In the sphere of personal knowledge, the question of the empirical application of knowledge is solved quite simply. The personal knowledge is associated with skills and therefore it is practically applicable in any situation. The personal knowledge is inalienable from the person and helps to understand the destiny of man. personal knowledge resolves the contradiction between the rational and the empirical. It turns into a skill and demonstrates its practical application.

\section{Methodological Potential of PhILOSOPHY OF EDUCATION}

In general, the education is associated with knowledge, understanding and development of the skills and abilities of the individual. Such discipline as the philosophy of education has taken the trouble to reflexively comprehend this process.

The methodological potential of the philosophy of education has the three main characteristics. First, it relies on traditional methods and approaches. Here it is necessary to single out the principle of objectivity and the principle of consistency. The holistic approach is of great importance, it is aimed at a holistic review of the situation. It is necessary to emphasize the special significance of the principle of development, which answers the question of how the phenomenon arose, through what stages passed, what it has become now. It is necessary to emphasize the special significance of the principle of development, which answers on the question: how the phenomenon arose, through what stages passed, what it has become now.

The method of comparative analysis, which compares the various paradigmatic settings, is also important. The principle of sociocultural determination has special significance, it shows the dependence of mental orientations on the spirit of the epoch. These methodological tools as well as the principle of historicism can be attributed to the classical methodological strategy.

However, the study of such a complex phenomenon as the philosophy of education requires a set of heuristic methods. The modern methodology includes a set of heuristic methods and models. The second group of heuristic methods is represented by A.F. Osborn's "brainstorming"[10]; G. Bush's structural and semantic model [11], the choice of 
the optimal regulator, the combination of rational and nonrational, intuitive-practical orientations. Such methods as the analogy method, the precedent method, the imitation method, have great practical value. The heuristic method of the reformulation of conditions and the purposes can appear effective also.

Thirdly, the modern methodologists record a shift towards cognitive practices and an interdisciplinary approach [12]. The advantage of cognitive practices is that they take into account the motivation, the value system, the goal setting, as well as the specific situation in the decisionmaking process. They have to be compatible with the demands of the current situation. Moreover, the cognitive practices give patterns of behavior that extend to the group representations and exert "normative pressure. The practice of expertise of the humanitarian situation has special value. It reveals the negative characteristics and risks of the educational process.

\section{V. "HOMO INTERNETICUS" AND NEGATIVE EFFECTS OF THE INFOCENTRIC WORLD}

Modern educational processes take place in new civil conditions, in which information technologies acquire a leading role. There are data according to which the information flow that falls on a modern person is 50 times more intensively, than at the beginning of the last century. In the current situation, the direct influence of the teacher and mentor is extremely reduced, and, on the contrary, the anonymous influence of network interaction is largely exaggerated. According to the modern western scientist A. Ray, the discussion about the dangers of incorporating modern technologies into our lives lags behind, at least, for five years [13].At the same time, the researchers are concerned by the fact that already now the infocentric world has produced a set of negative effects, including in the education system[14]. First, the system of moles of speech behavior is transformed. The language of Internet users is not restricted by any cultural framework. Secondly, human thinking acquires a clip-like character. We emphasize that "clip" means in translation "cut off", "crop". Our contemporary perceives the random and separate fragments, he learns to live with a discrete and fragmentary picture of the world. Under the press of information technology, the conceptual structure of thinking is supplanted by the clip-art. Causal conditioning of phenomena, a holistic perception of reality, the logic of the development of events - all this appears as pseudo-problems. The eclecticism wins a victory.

Thirdly, as the researchers note, a person covered by the Internet networks gives preference to visual images rather than to the semantic immersion in the text. Thus, infocentrism generates a negative effect, which causes both the skewed in the development of cognitive skills and deformation of analytical abilities. Thinking based on clips is connected with essentially short messages and is aimed at a momentary way of perception. All this has a negative impact on the logic of decision-making. The phase of analysis, thinking and finding the reasons and alternatives was lost. "Homo inretneticus" is easily manipulated, because the visual perception forms a dominant in the right hemisphere, disabling or inhibiting the functions of the left hemisphere, responsible for logic, conceptuality, cause-effect relationships. The constant consumption of clip information does not satisfy the need, but generates a craving for a new and new perception of it. The person experiences huge dependence on computers. In this regard, the problem of the impact of information technology on the human brain is acute. Psychologists compare information-dependence with the powerful dredges that predetermine behavioral deviations. There are violations of concentration, general absentmindedness, fatigue and overwork.

The significant negatives of Internet technologies are that they imitate the creative process. The opportunities provided by the Internet contribute to a wide spread of consumer attitudes toward ready-made Internet products. They cultivate activity in the direction of reproduction of samples which are already presented to the Internet space. However, despite all these negative effects, the information technologies are assumed as the basis "societies of knowledge". They are estimated as increased "resolving power" of a human brain as powerful "intermediaries" of modern existence. However, despite all these negative effects, the information technologies are assumed as the basis "societies of knowledge". They are estimated as increased "resolving power" of a human brain as powerful "intermediaries" of modern existence.

In our opinion, the complex and ambiguous processes of modern education should be tested by the expert community. The socio-humanitarian examination with the key figure of the expert takes as the guiding idea of technology "with a human face", based on the semantic and value interaction Now it is extremely important to think on the scale of "strategic" reason.

\section{CONCLUSION}

The article reveals a number of contradictions that take place in the modern transformations of the education process. First, the vector of transformations of the educational process is aimed at the formal imposition of a number of competencies, despite the existence of diverse methodological approaches and creative models. The shortcomings of the modern educational system, which is based on formal competencies, are due to the fact that they limit the scope of individual achievements to formal instructions, control the free manifestation and selfrealization of the individual. The obligatory system of competences limits possibilities for individual development and creative self-expression of the personality. Thereby the role of the subjects of the educational process is reduced to the level of "a peculiar construction material".

Secondly, the modern civilizational conditions reveal the enormous importance of "intellectual capital". Information technologies are estimated as the basis of "society of knowledge". At the same time, the philosophical meaning of modern educational transformations has been lost, recognizing the self-realization of personality as the main value. In contrast to the fact that the paidei model, known from antiquity, had three components in it: education, 
training and culture, and included a clearly expressed function of care.The Paideia model was aimed at forming a set of positive human qualities. It could be rethought and used in our time.

Another model of the educational process - «the model of personal knowledge» has a huge humanistic potential also.The author sought to show that personal knowledge, which is the immanent goal of the educational process, has the following advantages. First, they are inseparable from the person and help to understand his purpose. Secondly, the personal knowledge resolves the contradiction between the rational and the empirical. It turns into a skill and demonstrates its practical application. Thirdly, the personal knowledge integrates an intuition and rationality.

In modern conditions, the disciplinary organization of knowledge is supplemented by problem-oriented and interdisciplinary approaches. This allows us to fix the desire for integrity and on this basis to emphasize the philosophical meaning of the transformations of the educational process. The philosophy of education attaches special importance to heuristic methods and cognitive practices that must be compatible with the demands of the current situation. The advantage of cognitive practices is that they take into account motivation, value system, target orientations, as well as the specifics of the situation in the decision-making process. Thus, the dominance of the disciplinary representation of knowledge is replaced by integrative and systemic tendencies.

Thirdly, the author justifies the conclusion that, despite the presence of negative effects, reflection on the unsuccessful transformations of the educational process is significantly delayed. Moreover, it is weakly articulated and does not have a significant depth and conceptuality.

Fourth, the shift towards information technology produces significant deformations in the sphere of consciousness and cognitive processes. Visual perception forces out a conceptual system of thinking. The language of communication and verbal behavior are simplified. The desire to absorb all new and new network information is compared with strong dredges. There are violations of concentration of attention, the general absent-mindedness.

The main conclusion of the article is to justify that the system of true humanistic values must permeate the strategy of education. In other words, the education strategies must be subordinated to a system of true humanistic values. Even under existing conditions, the philosophical meaning of the transformations of the educational process must consist in reliance on philosophical wisdom and the ideals of genuine humanity. The institute of experts, scientists and philosophers should direct their creative efforts to the generation of humanistic educational models corresponding to their time.
[3] V.V. Davydov, "The theory of developmental learning". M .: Academy, 2004. $288 \mathrm{p}$

[4] T.G. Leshkevich, "The problem of qualitative "unpacking" of meanings of life", Scientific thought of the Caucasus. Rostov n/D., Publishing house SKNTS VS SFU, 2014, №4 p.14-22.

[5] O.V. Arkhipova, "The idea of education in the context of postnonclassical culture", Abstract of the thesis for the degree of Doctor of Philosophy. St. Petersburg, 2012, pp. 4-22.

[6] Y. Noh, "The Bodily Basis of a Conceptual system", Philosophy and culture, Vol. 3. Epistemology, Seul, 2008.

[7] A. M. Olson, "Paydeya and globalism", Global studies. Encyclopedia M, Publishing house Raduga, 2003. PP. 775-777.

[8] M. Polanyi., «Personal Knowledge», University of Chicago Press, 2012, 442

[9] The Cambridge Dictionary of philosophy, General Editor Robert Audi. Cambridge, University Press, 1995 p.584.

[10] A.F. Osborn, "Applied Imagination: Principles and Procedures of Creative Problem Solving”, New York: Charles Scribner's Sons, 1953, $317 \mathrm{p}$.

[11] G. Ya.Bush, "Birth of the inventive ideas". Riga: Publishing House "Liesma", 1976, 127 p.

[12] "Post-nonclassical practices: the experience of conceptualization". St. Petersburg, Publishing House World, 2012, 535p.

[13] A.M. Rieu, "The epistemological and philosophical situation of mind techno-science", Electronic Publication , URL.http://www/ stanford.edu/group/SHR/4-2/text/rieu/html

[14] T.V. Semenovskikh, "The phenomenon of "clip thinking" in the educational high school environment". Internet Journal "Science of science". $\quad$ Issue 5 (24), $\quad$ October 2016. http://naukovedenie.ru/PDF/105PVN514.pdf]

\section{REFERENCES}

[1] Philosophy on Education. Encyclopedia. N. Y., 1997.

[2] Creative Pedagogy. Methodology, theory, practice, M., Bean, 2011. 